\title{
Uso de entulho de construção civil como sistema de cobertura para abatimento de drenagem ácida de mina em uma mina abandonada de pirita
}

\section{Use of solid residues from civil construction as a covering system for acid mine drainage abatement in an abandoned pyrite mine}

Natália Cristiane de Moraes

Mestre em Engenharia Mineral, PPGEM/UFOP

nataliacristianem@yahoo.com.br

José Margarida da Silva

Prof. do Departamento de

Engenharia de Minas/EM/UFOP

jms@demin.ufop.br

\section{Hernani Mota Lima}

Prof. do Departamento de

Engenharia de Minas/EM/UFOP

hernani.lima@ufop.br

\section{Resumo}

Em Ouro Preto/MG, pirita foi extraída em uma antiga mina, denominada Jazida de Pirita, durante os anos de 1930 a 1967. Considerada como uma das melhores jazidas de pirita no Brasil, essa mina foi explotada com o objetivo de atender à demanda por ácido sulfúrico, para fabricação de explosivos, da Fábrica Presidente Vargas em Piquete/SP. O local da mina está abandonado e tem, como principais passivos ambientais, a instabilidade das encostas e a geração de drenagem ácida. Atualmente, o local tem sido utilizado para lançamento clandestino de entulho na área o que contribui para o aumento do impacto ambiental. A Prefeitura de Ouro Preto, por sua vez, tem intenção de usar parte da área da mina para disposição de resíduo de construção civil. Esse artigo apresenta os resultados dos ensaios cinéticos realizados, em colunas de lixiviação, para avaliação do potencial de geração de drenagem ácida, em amostras coletadas da mina de pirita, e analisa a possibilidade de controle ou de minimização da drenagem ácida, utilizando-se do entulho como cobertura. Os resultados encontrados mostram que a utilização do entulho como sistema de cobertura foi eficiente na redução de acidez, na concentração de metais e sulfato presentes nas colunas analisadas.

Palavras-chave: Drenagem ácida de minas, entulho, colunas de lixiviação, Mina de Pirita.

\begin{abstract}
In Ouro Preto/MG, pyrite was exploited at an old mine from 1930 through 1967. Considered as one of the best resources of pyrite in Brazil, this mine was exploited in order to supply sulfuric acid for explosives manufacturing, at the President Vargas Plant in Piquete/SP. The mine site is abandoned and has slope instability and acid leakage generation as the main environmental liabilities. Lately, the site has been used for illegal deposition of all sorts of urban waste. The Ouro Preto Administration, on its turn, has the intention of using part of the mine site for the disposal of solid residues of civil construction. This paper presents the results of kinetic tests carried out, in leaching columns, to assess the acid mine drainage potential in samples collected from the mine site and to evaluate the possibility of controlling and minimizing acid generation by using solid residues as a covering system. Laboratory results show that
\end{abstract}


cover with solid residues of civil construction was effective in the reducing the acidity, concentration of metals and sulfate.

Keywords: Acid Mine Drainage, debris, leaching columns, Pyrite’s Mine.

\section{Introdução}

Entre os municípios de Ouro Preto e de Mariana, região central do Estado de Minas Gerais, Brasil, localiza-se uma das antigas minas de pirita descrita por Djalma Guimarães. A mina, conhecida como Mina de Pirita, possuiu várias denominações, sendo a mais comum a de Jazida de Pirita. A mesma é também erroneamente denominada de Mina de Ojô, embora esta se localize a nordeste da área estudada.

A Mina de Pirita foi intensamente lavrada no período compreendido entre a Era Vargas e o início da década de 60, do século passado, pela Empresa Mineira de Pirita Ltda, tendo sido desativada pouco tempo depois. $\mathrm{Na}$ época, ela foi considerada como uma das melhores jazidas de pirita do Brasil, com uma reserva estimada de 10.000.000 toneladas (Lacourt, 1938). Foi explotada com o objetivo de se produzir ácido sulfúrico, utilizado principalmente para fins bélicos (confecção de pólvora) na Fábrica Presidente Vargas. Sabe-se que, durante a explotação, grandes quantidades de pirita foram mobilizadas e oxidadas, produzindo drenagem ácida de minas.

O processo de formação de drenagem ácida ocorre pela ação intensiva e prolongada do oxigênio atmosférico e da água sobre minerais sulfetados, que podem estar presentes em várias partes da mina, como cavas, pilhas de estéril, barragem de rejeitos e outras obras, como barragens de enrocamento e tú-

\section{Materiais e métodos}

Nesse trabalho, foi utilizado entulho de construção civil em colunas de lixivia-

ção como sistema de cobertura para o abatimento da DAM. A seguir, descrevem-se pularmente conhecidos como entulhos. O Município de Ouro Preto já possui instituídos alguns instrumentos de gestão urbana, entre eles o Plano Diretor (Lei Complementar no 29 de 28/12/06), que tem, como uma de suas políticas setoriais, a Gestão de Resíduos Sólidos.

Mariano (2008) realizou um estudo sobre as áreas de disposição ilegal de entulho na região de Ouro Preto e a Mina de Pirita foi um dos pontos diagnosticados como bota-fora. Ela foi classificada como Zona de Intervenção Especial (ZIE) e definida como uma área que demanda recuperação ambiental, em função da presença de processos erosivos ou de outras formas de degradação ambiental resultantes da ação do homem sobre o ambiente. A mina foi considerada o melhor local para a deposição de entulho, por ser uma ZIE, possuir baixa declividade, ter uma capacidade volumétrica considerável e ser de fácil acesso.

Tendo como base esse contexto, esse trabalho objetivou estudar a influência do entulho de construção sobre a drenagem ácida de minas através de ensaios, com colunas de lixiviação, considerados como método cinético muito utilizado na previsão do potencial de drenagem ácida. Tal método pretende imitar os processos encontrados nos locais da mina, normalmente a uma taxa acelerada (U.S. EPA, 1994). Através dele, pode-se avaliar diferentes variáveis no processo de produção de acidez.

\section{Amostragem}

A localização e o número de pontos de amostragem na Mina de Pirita foram definidos através de visitas a campo e, também, de acordo com as condições favoráveis à coleta. Os locais foram definidos em virtude de pontos com surgência de água com $\mathrm{pH}<3,0$. A Tabela 1 apresenta a localização dos pontos, com as coordenadas e o $\mathrm{pH}$ correspondente.

As amostras da mina foram cole- tadas manualmente com pá, picareta e enxada, tomando-se cuidando de se retirar uma camada superior a $30 \mathrm{~cm}$ de solo devido ao carreamento de sedimentos provenientes da parte superior da mina e ao elevado estado de alteração do solo. Posteriormente, as amostras foram acondicionadas em sacos plásticos. No Laboratório de Geotecnia da UFOP, elas foram destorroadas, as etapas de amostragem, a realização dos ensaios e os resultados obtidos. passadas numa peneira convencional de construção civil, para a homogeneização do material. Após o peneiramento, as amostras foram secas ao ar livre e, logo após, pesadas. Retirou-se uma fração representativa de $7 \mathrm{~kg}$ de cada uma para mistura e foi feito o quarteamento pelo método cônico, resultando no material aqui codificado como AM (amostras da mina). 
O entulho utilizado provém de reforma em prédio da própria UFOP, constituído de pedaços de concreto, de tijolos de cerâmica, de argila, de concreto, de gesso e de telhas de amianto,

Tabela 1

Localização dos pontos amostrados e os correspondentes valores de $\mathrm{pH}$.

* Coordenadas obtidas com GPS. DATUM: SAD 1969 - Zona: 23S/ Projeção: UTM.

\section{Procedimentos}

Para determinação da composição mineralógica do entulho e do material da mina, foi utilizada a técnica de difração de raio X. As amostras submetidas a difratometria e a digestão foram pulverizadas de modo a se obter uma granulometria inferior a 200 mesh. O equipamento utilizado na difração foi difratômetro equipado com tubo de ferro com monocromador de grafite $(\lambda=$ $1,9360 \AA$ A), em operação no laboratório do DEQUI/ICEB/UFOP.

Para avaliar o processo de formação e o abatimento da drenagem ácida,

Tabela 2

Principais características das colunas I, II, III, IV e V.

não obedecendo, nenhuma metodologia de ensaio.

As colunas I e II possuíam finalidade de servir como referência para resultados obtidos nas outras colunas e identificar características físico-químicas e comportamento dos materiais utilizados. Os objetivos das colunas III e IV foram avaliar a qualidade do abatimento da drenagem ácida oferecida pela cobertura de entulho e verificar se a proporção de entulho em relação ao material da mina seria satisfatória no processo. A coluna $\mathrm{V}$ classificados como A e C pela NBR ABNT 15114. No Laboratório de Processamento de Minérios da UFOP, tal entulho foi cominuído em britadores de mandíbulas e de rolos e classificado com uma peneira de construção civil, a fim de se retirarem as partículas maiores e de igualar a sua granulometria ao material da mina. Todo o entulho foi homogeneizado e quarteado pelo método cônico.

\begin{tabular}{c|c|c|c}
\hline \multirow{2}{*}{ Pontos } & \multicolumn{2}{|c|}{ Coordenadas* $^{*}$} & \multirow{2}{*}{$\mathrm{PH}$} \\
\cline { 2 - 4 } & $\mathrm{X}$ & $\mathrm{Y}$ & \\
\hline 1 & 657389 & 7743657 & 2,91 \\
\hline 2 & 657419 & 7743668 & 2,74 \\
\hline 3 & 657383 & 7743691 & 6,71 \\
\hline 4 & 657411 & 7743699 & 4,94 \\
\hline 5 & 657453 & 7743727 & 6,94 \\
\hline
\end{tabular}

foram montadas 5 colunas de lixiviação, denominadas I a V, com diferentes objetivos e dimensões. Para ensaios de lixiviação e para a análise de lixiviados, foram utilizados, como referência, procedimentos de Method 1627: Kinetic Test Method for the Prediction of Mine Drainage Quality (EPA, 2009) e Greenberg et al. (1992).

Os ensaios de lixiviação consistiram em percolar diariamente água deionizada pelo material da mina (AM) e pelos sistemas de coberturas acrescentados, monitorando-se diariamente os diversos parâmetros químicos e físico-químicos do lixiviado. Para isso, a quantidade de água deionizada a ser lixiviada pelas colunas foi calculada com base na precipitação média anual ocorrida na cidade de Ouro Preto $(1.724 \mathrm{~mm})$ e nas dimensões das colunas. A Tabela 2 mostra o resumo geral da composição das colunas de lixiviação, a quantidade de material introduzido, a duração dos ensaios e a quantidade de água introduzida diariamente. A quantidade de material introduzida nas colunas de lixiviação foi escolhida aleatoriamente,

\begin{tabular}{c|c|c|c|c}
\hline Colunas & Tipo de material utilizado & $\begin{array}{c}\text { Quantidade de } \\
\text { material (kg) }\end{array}$ & $\begin{array}{c}\text { Duração dos } \\
\text { ensaios (dias) }\end{array}$ & $\begin{array}{c}\text { Volume de água } \\
\text { introduzido } \\
\text { diariamente (mL) }\end{array}$ \\
\hline I & $\begin{array}{c}\text { Amostra de material da } \\
\text { mina (AM) }\end{array}$ & 14,3 & 30 & 955 \\
\hline II & Entulho (E) & 8,3 & 30 & 241 \\
\hline III & E + AM & $7,5+7,5$ & 23 & 955 \\
\hline IV & E + AM & $2+8$ & 40 & 955 \\
\hline V & E + CaO +AM & $1+0,1+3,0$ & 40 & 241 \\
\hline
\end{tabular}

objetivou simular influência da camada de aditivo alcalino (cal) entre o material da mina e o entulho, na proporção 1: 3 . A cal foi escolhida devido a seu baixo custo relativo no tratamento de drenagens com elevada acidez e alta concentração de sulfatos e por reagir rapidamente no sistema. Os ensaios das colunas IV e V foram prolongados por 10 dias.

Diariamente foram coletadas e armazenadas as soluções drenadas (lixiviados) das colunas para a determinação do $\mathrm{pH}$, Eh (potencial redox), acidez, alca- linidade, metais, condutividade elétrica (CE), sulfato e temperatura.

As medidas dos valores do $\mathrm{pH}$ e Eh foram feitas em um pHmetro digital, cuja calibragem foi efetuada com soluçõestampão do fabricante - $\mathrm{pH} 4,01$ e 6,86 (pH) e $228 \mathrm{mV}$ (Eh).

As determinações dos metais foram feitas utilizando-se de ICP-OES (Espectrofotômetro de Emissão Óptica com Fonte Plasma Indutivamente Acoplado) e foram realizadas no Laboratório de Geoquímica Ambiental/UFOP. Para isso, 
as amostras foram coletadas, filtradas, armazenadas em frascos de polietileno e devidamente acidificadas com 3 gotas de $\mathrm{HNO}_{3}$, a $10 \mathrm{~mol} / \mathrm{L}$, para se evitarem possíveis reações de precipitação.

\section{Resultados e discussões}

\section{Difração de raio $X$}

A difratometria evidenciou a presença de quartzo $\left(\mathrm{SiO}_{2}\right)$, caulinita $\left(\mathrm{Al}_{2} \mathrm{Si}_{2} \mathrm{O}_{5}(\mathrm{OH})_{4}\right)$ e hematita $\left(\mathrm{Fe}_{2} \mathrm{O}_{3}\right)$ em todas as amostras investigadas, exceto na amostra introduzida nas colunas de lixiviação. Dos cinco pontos amostrais, foi também diagnosticada goethita
As soluções lixiviadas pelas colunas foram coletadas diariamente e armazenadas em frascos de polietileno de $250 \mathrm{~mL}$ e analisadas semanalmente, com auxílio de turbidímetro, devidamente calibrado. As concentrações de sulfato foram obtidas através de uma curva-padrão.

Para a determinação da acidez e da alcalinidade, utilizou-se o método titulométrico descrito por Greenberg (1992).

\section{Monitoramento das colunas de lixiviação}

As Figuras de 1 a 4 apresentam os resultados das concentrações de metais lixiviados durante o período de monitoramento. A Tabela 3 apresentada sumariza os valores observados para os parâmetros monitorados.
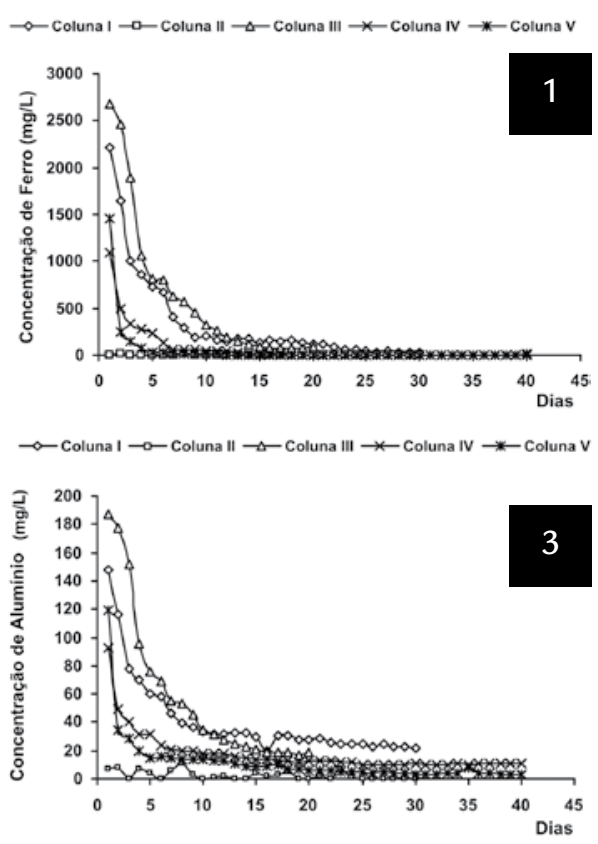

\begin{tabular}{|c|c|c|c|c|c|}
\hline \multirow{2}{*}{ Parâmetros } & \multicolumn{5}{|c|}{ Colunas } \\
\hline & 1 & II & $\mathrm{III}^{*}$ & IV & v \\
\hline $\mathrm{pH}$ & $1,86-2,43$ & $\begin{array}{r}\text { Oscilou entre } \\
11,5\end{array}$ & $1,87-2,64$ & $2,24-3,33$ & $2,05-3,63$ \\
\hline Eh $(m V)$ & $611,1-453,5$ & $\begin{array}{c}\text { Forte oscilação entre - } \\
9,5 \text { e } 155,4\end{array}$ & $585,8-615,3^{* *}$ & $592,1-425,6$ & $607,2-412,5$ \\
\hline $\mathrm{CE}(\mathrm{mS} / \mathrm{cm})$ & $11,019-4,288$ & $3,824-2,168$ & $12,651-4,005$ & $7,918-2,398$ & $9,625-2,001$ \\
\hline $\begin{array}{c}\text { Acidez } \\
\left(\mathrm{mg} / \mathrm{L} \mathrm{CaCO}_{3}\right)\end{array}$ & $304,75-81,65$ & - & $1748,0-95,39$ & $634,28-18,90$ & $804,30-7,27$ \\
\hline $\begin{array}{l}\text { Alcalinidade } \\
\left(\mathrm{mg} / \mathrm{L} \mathrm{CaCO}_{3}\right)\end{array}$ & - & $\begin{array}{c}\text { Valores oscilando entre } \\
309,4 \text { (início) e } 26,35 \\
\left(20^{\circ} \text { dia) }\right.\end{array}$ & - & - & - \\
\hline $\mathrm{SO}_{4}{ }^{2-}(\mathrm{mg} / \mathrm{L})$ & $9563,7-2551,0$ & \begin{tabular}{c|} 
Forte oscilação entre \\
1152,5 e 1848,9
\end{tabular} & $14238,5-2329,9$ & $6168,4-1599,6$ & $2312,3-1434,9$ \\
\hline
\end{tabular}
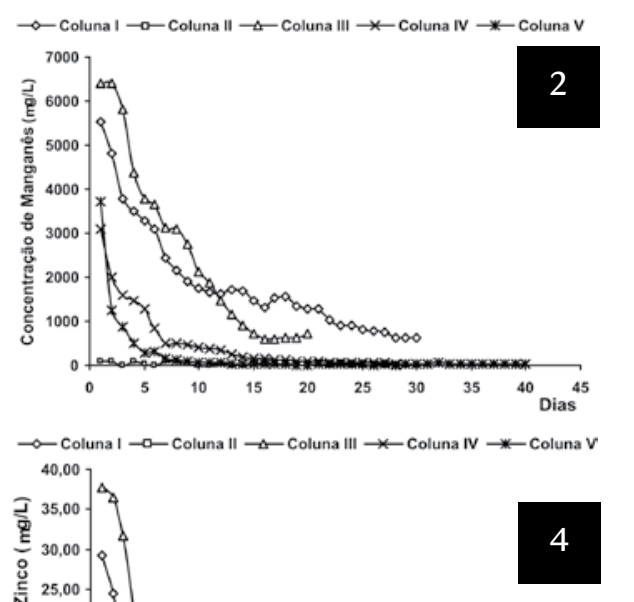

( $\mathrm{FeOOH}$ ), em dois dos pontos, muscovita $\left(\mathrm{KAl}_{2}\left(\mathrm{AlSi}_{3} \mathrm{O}_{10}\right) \mathrm{OH}_{2}\right)$, exceto no ponto 1 , albita $\left(\mathrm{NaAlSi} 3 \mathrm{O}_{8}\right)$, somente no ponto 3 e no entulho, rutilo $\left(\mathrm{TiO}_{2}\right)$ : pontos 4 e 5 , e dolomita $\left(\mathrm{CaMg}\left(\mathrm{CO}_{3}\right)_{2}\right)$, na amostra introduzida nas colunas.

Tal mineralogia é compatível com as rochas locais e com os resultados da caracterização fisico-química.

Destaca-se que a pirita não foi descrita por esse método, mas foi vista a olho nu em campo e comprovada a existência por trabalho de Martins (2005).

metais analisados na coluna III, que possuía uma quantidade inferior de material da mina que a coluna I. Supõe-se que esses altos valores estejam relacionados ao estado de alteração e à granulometria das amostras introduzidas na coluna.

Figura 1

Concentração de ferro das soluções lixiviadas das colunas I, II, III, IV e V.

Figura 2

Concentração de manganês das soluções lixiviadas das colunas I, II, III, IV e V.

Figura 3

Concentração de alumínio das soluções lixiviadas das colunas I, II, III, IV e V.

Figura 4

Concentração de zinco das soluções lixiviadas das colunas I, II, III, IV e V.

Tabela 3

Resumo geral dos valores observados para os parâmetros monitorados durante os ensaios com as colunas de lixiviação.

* O monitoramento das soluções da coluna III foi impedido no $23^{\circ}$ dia, devido ao entupimento do dreno. * Os valores de Eh da coluna III exibiram o comportamento de queda até o $14^{\circ}$ dia. Após esse período, os valores começaram a se elevar devido ao entupimento do dreno da coluna. 
Os valores do $\mathrm{pH}, \mathrm{Eh}, \mathrm{CE}$, acidez e concentração de $\mathrm{SO}_{4}{ }^{2-}$ das colunas I, III, IV e V são referentes aos valores observados no intervalo compreendido entre o início e o fim dos experimentos. Os valores da coluna II, exceto a CE, oscilaram constantemente durante $\mathrm{O}$ monitoramento.

Os valores do $\mathrm{pH}$ das colunas I, III, IV e $\mathrm{V}$ foram considerados ácidos ( $\mathrm{pH}<7$ ). Ressalta-se que a elevação observada, na coluna I, deve-se à presença de dolomita identificada pelas análises de difratometria. Nas outras colunas (III, IV e V), além da presença da dolomita, o entulho e a cal contribuíram para a elevação do $\mathrm{pH}$ observado. O caráter básico $(\mathrm{pH}>7)$ apresentado pelas soluções lixiviadas da coluna II, deve-se, em parte, à presença do calcário, que faz parte da composição do cimento utilizado na construção civil.

Observa-se que os valores do Eh foram elevados, exceto para a coluna II, que oscilou entre $-9,5$ e $155,4 \mathrm{mV}$, indicando um ambiente redutor. Os valores

\section{Conclusões}

A utilização do entulho como sistema de cobertura foi eficiente na redução de acidez, na concentração de metais e sulfato presentes nas colunas analisadas. Destaca-se a importância de se utilizarem aditivos alcalinos junto com o entulho, para uma melhor redução desses parâme-

\section{Agradecimentos}

Os autores agradecem à Fundação Gorceix e ao PPGEM (Programa de Pós-Graduação em Engenharia Mineral), elevados das outras colunas refletem um ambiente oxidante, favorecendo a oxidação de sulfetos. Valores de Eh > 500 $\mathrm{mV}$ promovem a oxidação do $\mathrm{Fe}^{3+}$ (Mend Program, 1991), fato que pode ser comprovado pela grande quantidade de ferro que foi lixiviada nas soluções analisadas.

Nas colunas monitoradas, os valores de CE foram elevados, exibindo uma forte redução nos primeiros dias de monitoramento, inclusive para a coluna II. Esse parâmetro, junto com a acidez, refletiu a elevada quantidade de íons liberados para as soluções. A acidez das soluções lixiviadas deu-se através da elevada quantidade de sulfato presente nas quantidade de metais lixiviados, principalmente $\mathrm{Al}, \mathrm{Fe}$ e $\mathrm{Mn}$, para as soluções. Esse fato pode ser confirmado pela forte coloração amarela e pela viscosidade das soluções analisadas, que, em $\mathrm{pH}<3,5$, precipitam o íon $\mathrm{Fe}^{3+}$, que possui uma coloração amarelo-alaranjada. Ressalta-se a eficiência da camada de entulho sobre amostras e, também, através da grande

o material da mina, que reduziu em mais de $90 \%$ a acidez das soluções das colunas III e IV. A referida camada, junto com a cal, reduziu, em 99\%, o valor da acidez inicial das soluções da coluna V.

A alcalinidade do entulho da coluna II deve-se, principalmente, à presença do calcário contido na composição do cimento, do gesso e dos silicatos detectados pela difração de raio X (quartzo, muscovita, caulinita e albita). Os valores encontrados oscilaram entre 309,4 (início) e $106,25 \mathrm{mg} / \mathrm{L} \mathrm{CaCO}_{3}$ (fim).

A concentração de sulfato, determinada pelo método turbidimétrico, foi superior a $1000 \mathrm{mg} / \mathrm{L}$ em todas as colunas. O sulfato é um produto direto da oxidação dos sulfetos. Nas colunas I, III, IV e V, houve uma forte queda de concentração nos primeiros dias, destacando-se a eficiência do entulho sobre as reduções e o elevado estado de alteração das amostras, em virtude das elevadas concentrações apresentadas durante os ensaios.

tros. A adição de entulho não foi eficiente na elevação do $\mathrm{pH}$ e na redução do Eh, que são consideradas as variáveis principais dos processos geoquímicos para controle da solubilização dos metais.

O sistema de cobertura empregado nas colunas aponta para uma alternativa

pelo apoio financeiro para o desenvolvimento do trabalho; ao pessoal dos Laboratórios de Geotecnia, Geoquímica interessante para a remediação da drenagem ácida de minas, um problema que hoje assombra as minerações devido aos inúmeros impactos ambientais. Entretanto mais estudos devem ser realizados, atentando-se para a elevada concentração de sulfatos presente no entulho.

Ambiental, Química e Tratamento de Minérios da UFOP pela realização das etapas dos ensaios.

\section{Referências bibliográficas}

ASSOCIAÇÃO BRASILEIRA DE NORMAS TÉCNICAS - ABNT. NBR 15114: Resíduos sólidos da construção civil - áreas de reciclagem - Diretrizes para projeto, implantação e operação. Rio de Janeiro - RJ, 2004. $7 \mathrm{p}$.

FARFAN, J.R.J., BARBOSA FILHO,O., SOUZA,V.P. Avaliação do potencial de drenagem ácida de rejeitos da indústria mineral. Rio de Janeiro: CETEM/MCT, 2004. n.30. 58p. (Série Tecnologia Mineral).

GREENBERG, A.E., CLESCERI, L.S., EATON, A.D. Standard Methods for the examination or water and wastewater. (18ed.).Washington: American Public Health Association, 1992.

LACOURT, F. Barita e pirita no município de Ouro Preto - Minas Gerais. Revista Mineração e Metalurgia, 1938, v.II, n.11, p.298-301.

MARIANO, T.R.B. Diagnóstico - plano integrado de gerenciamento dos resíduos sólidos da construção civil no município de Ouro Preto. Ouro Preto: Universidade Federal de Ouro Preto, 2008. 82p. (Monografia de Graduação).

MARTINS, C.M. Rastreamento geoquímico de possiveis contaminações remanescentes de mineraçães de pirita no município de Ouro Preto, Quadrilátero Ferrífero, Minas Gerais. Ouro Preto: Universidade Federal de Ouro Preto, Escola de Minas, Departamento de Geo- 
logia, Programa de Pós-Graduação em Evolução Crustal e Recursos Naturais, 2005. 221p. (Dissertação de Mestrado).

MEND PROGRAM. Environment Canada, Acid Rock Drainage Prediction Manual. Mend, Project 1.16.1b, CANMET, 1991.

U. S. ENVIRONMENTAL PROTECTION AGENCY - U. S. EPA "Acid Mine Drainage Prediction”. Technical Document, EPA 530-R-94-036.1994, p. 1-32.

U. S. ENVIRONMENTAL PROTECTION AGENCY - U. S. EPA. "Method 1627: Kinetic Method for the Prediction of Mine Drainage Quality". Technical Document, EPA 821-R09-002. 2009, p. 1-40.

VASCONCELOS, F. M., SANTOS, L.R.G., SOUSA, H.A. Global acid rock drainage (GARD) Guide: uma proposta de consolidação das metodologias de investigação e gestão da drenagem ácida de mina. In: CONGRESSO BRASILEIRO DE MINA A CÉU ABERTO, 5. Anais... Belo Horizonte, 2008. p.1-6.

Artigo recebido em 13 de abril de 2010. Aprovado em 23 de novembro de 2010.

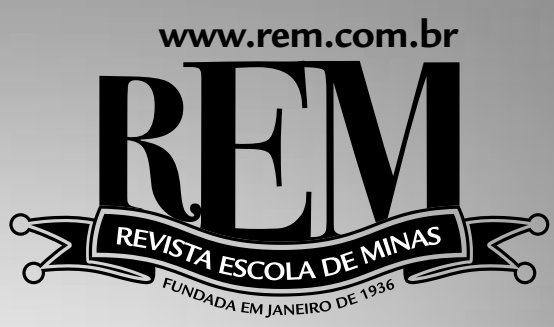

\title{
ANUNCIE NA REM - REVISTA ESCOLA DE MINAS.
}

\author{
Pedidos de inserção, negociações e consultas: \\ RBC EDITORAÇÃO ELETRÔNICA \\ Luciano Borba \\ (31) 35514730 \\ diretor.comercial@rem.com.br
}

